\title{
Romosozumab: a novel bone anabolic treatment option for osteoporosis?
}

\author{
Katharina Kerschan-SchindI (iD)
}

Received: 26 August 2019 / Accepted: 13 November 2019 / Published online: 19 December 2019

(C) The Author(s) 2019

\begin{abstract}
Summary Research into the drug romosozumab began with the investigation of patients with excess bone formation. The understanding of the wingless-type mouse mammary tumor virus integration site (Wnt) signaling pathway in bone metabolism identified the negative regulator of bone mass sclerostin as a potential target for the treatment of osteoporosis. Preclinical studies confirmed this idea because they showed that sclerostin antibodies have the potential to increase bone formation. Biochemical analyses of clinical studies showed a significant increase in bone formation markers, which then slowly decreased within a year. This was accompanied by a particularly initially pronounced decrease in bone resorption. This dual mechanism of action led to an increase in bone mineral density and a significant reduction in fracture risk. Clinical vertebral fractures decreased by between 28 and 36\%, nonvertebral fractures shown in a post hoc analysis by $42 \%$. Romosozumab is administered once a month in the form of two injections. At the puncture site, reactions occur in about $5 \%$. The most significant side effects are cardiovascular. In phase III studies, the number of serious cardiovascular complications was not significantly, albeit numerically, higher than in the control group. In Japan, South Korea, Canada, Australia, and the USA, osteoporosis patients at a high risk of fracture may already be treated with romosozumab (Evenity). Approval in the European Union was granted by 2019-12-12.
\end{abstract}

Keywords Sclerostin · Romosozumab · Blosozumab · Side effects

\footnotetext{
K. Kerschan-Schindl $(\bowtie)$

Department of Physical Medicine, Rehabilitation and Occupational Medicine, Medical University of Vienna, Waehringer Guertel 18-20, 1090 Vienna, Austria Katharina.Kerschan-Schindl@meduniwien.ac.at
}

\section{Romosozumab: eine neue Therapieoption bei Osteoporose mit anaboler Wirkung auf den Knochen}

Zusammenfassung Die Erforschung des Medikaments Romosozumab nahm ihren Anfang in der Untersuchung von Personen mit übermäßiger Knochenbildung. Mit dem Verständnis des Wnt(„winglesstype mouse mammary tumor virus integration site“)Signalwegs wurde Sclerostin, ein negativer Regulator der Knochenmasse, als potenzieller Angriffspunkt in der Osteoporosetherapie identifiziert. Präklinische Studien bestätigten dieses Konzept, denn sie zeigten, dass durch Sclerostin-Antikörper die Knochenbildung gesteigert werden kann. Biochemische Analysen klinischer Studien ergaben einen deutlichen Anstieg der Marker für die Knochenbildung, welche dann langsam innerhalb eines Jahres abfielen. Dies wurde begleitet von einem anfangs besonders stark ausgeprägten Abfall der Knochenresorption. Dieser duale Wirkmechanismus führte $\mathrm{zu}$ einem Anstieg der Knochenmineraldichte und einer signifikanten Reduktion des Frakturrisikos. Klinische vertebrale Frakturen nahmen zwischen 28 und $36 \%$ ab, nichtvertebrale Frakturen gezeigt in einer post hoc Analyse um $42 \%$. Die Gabe von Romosozumab erfolgt einmal monatlich in Form von 2 Injektionen. An der Einstichstelle kommt es in etwa $5 \%$ zu Reaktionen. Die bedeutendsten Nebenwirkungen finden sich im kardiovaskulären Bereich. In den Phase-III-Studien war die Anzahl der schwerwiegenden kardiovaskulären Komplikationen nicht signifikant, aber numerisch höher als in der Kontrollgruppe. In Japan, Südkorea, Kanada, Australien und den USA können Osteoporosepatienten mit hohem Frakturrisiko bereits mit Romosozumab (z. B. Evenity) behandelt werden. In der Europäischen Union ist das Präparat seit dem 12.12.2019 zugelassen. 
Schlüsselwörter Sclerostin · Romosozumab · Blosozumab $\cdot$ Nebenwirkungen

In healthy adults, bone resorption and bone formation are coupled. The process of bone remodeling is essential for the maintenance of bone mass. With increasing age, bone loss-a deficit of bone formation relative to bone resorption [1]—occurs. The insufficiency of osteoblast activity is caused by molecular mechanisms.

Essential for osteoblast differentiation and activity is the wingless-type mouse mammary tumor virus integration site (Wnt) pathway. Activation of the canonical anabolic Wnt/ß-catenin pathway occurs by binding of Wnt proteins to the extracellular part of the receptor complex consisting of frizzled (FRZ) and lipoprotein receptor-related proteins 5 and 6 (LRP-5 and LRP-6). Generated signals inhibit the activity of glycogen synthase kinase 3 (GSK 3) and destroy the B-catenin destruction complex. Stabilized $\beta$-catenin translocates into the nucleus and induces the transcription of osteoblastic proteins [2]. Wnt proteins, co-receptors, intracellular molecules, and transcription factors tightly regulate Wnt signaling [2]. Wellknown modulators and important inhibitors of this canonical Wnt pathway are dickkopf 1 (Dkk 1) and sclerostin $[3,4]$.

\section{Sclerostin}

Sclerostin was first recognized when diseases associated with high bone mass caused by mutations of the SOST gene were studied. Defects in the SOST gene were described as early as in the 1950s, [5, 6]: Van Buchem disease or "hyperostosis corticalis generalisata familiaris" is caused by deletion of an element of the SOST gene. Sclerosteosis, which is mainly found in South Africa, is the result of a homozygous mutation in the SOST gene. In both diseases, loss of function of the negative regulator of bone formation sclerostin leads to abnormal formation of bone. Due to narrowing of the cranial nerves' foramina, clinical symptoms like facial palsy, hearing impairments, or raised intracranial pressure occur [7, 8]. In sclerosteosis, the more severe disease, patients may also suffer from syndactyly.
Sclerostin, the product of the SOST gene, is a glycoprotein consisting of about 200 amino acids. Sclerostin mRNA has also been found in chondrocytes, kidney, lung, vasculature, and heart [9]. However, sclerostin is supposed to be mainly produced by bone matrix-embedded osteocytes. The mode of action of this Wnt antagonist is binding to and thus inactivating LRP [10]. Consequently, osteoblast differentiation and activity are reduced.

Despite the local action of sclerostin, biochemical analyses of circulating sclerostin seem to give a good impression of sclerostin levels in bone [11, 12]. Serum sclerostin levels are regulated by physiologic and pathophysiologic conditions. Although the expression of sclerostin was not altered in aged osteoblasts in an in vitro study [13], all clinical studies [14-17], except for one which also included subjects with chronic diseases like diabetes mellitus [18], found a positive correlation with age. In men as well as in women, the age-associated increase of serum sclerostin levels may be induced by the age-associated decline of estrogen [14]. Two studies detected higher serum sclerostin levels in men than in women [14, 17]. Amrein and coauthors [15], however, could not find a sex-specific difference after adjustment for age, bone mineral content, physical activity, body mass index, and renal function. Seasonal changes, with higher levels during wintertime, have also been described [19]. Since osteocytes are the main mechanosensors in bone, it is not surprising that sclerostin expression depends on mechanical loading. In an experimental setting, mechanical stimulation of bone (ulna) reduced the expression of sclerostin [20] and SOST-/- mice have been shown to be resistant to the bone loss caused by mechanical unloading [21]. In humans, study results differ a little bit. An exercise program lasting 12 months (resistance or jump training) led to decreases in serum sclerostin levels [22], but except for our investigation on ultradistance runners [23], no other trial detected a decrease of sclerostin following an acute exercise bout. The increase of inflammatory cytokines has been shown to be associated with the transient increase of serum sclerostin following a single workout [24]. Immobilized stroke patients had higher sclerostin levels than controls [25].

Considering the low or even unmeasurable serum levels of sclerostin in Van Buchem disease and scleros-

Table 1 Association of the serum sclerostin level with bone mineral density (BMD), bone turnover markers (BTMs), and fracture risk

\begin{tabular}{|l|l|l|l|l|}
\hline Population & Association with BMD & Association with BTM & Association with fracture & Reference \\
\hline Older women & Positive & $?$ & Positive & {$[26]$} \\
\hline Postmenopausal women & No association except total body BMD & Negative & Positive & {$[16]$} \\
\hline Postmenopausal women & Positive & Negative & No association & {$[27]$} \\
\hline Older men & Positive & Negative & Negative & {$[28]$} \\
\hline Institutionalized elderly women & Positive (SOS calcaneus) & Negative & No linear association & {$[29]$} \\
\hline Elderly subjects & Positive (SOS calcaneus) & Negative & $?$ & {$[17]$} \\
\hline SOS speed of sound & & & & \\
\hline
\end{tabular}


teosis, the thought that high sclerostin levels lead to loss of bone mass and bone strength with an increased fracture risk is obvious. Therefore, several studies [16, 17, 26-29] evaluated the association between serum sclerostin level on one hand and bone mineral density (BMD), bone turnover markers (BTMs), and risk of fracture on the other hand (Table 1). Although low BMD is expected in subjects with high sclerostin levels, all studies so far have found a positive association between serum sclerostin and BMD. A possible explanation is that more bone means a higher number of osteocytes able to secrete sclerostin. All investigations found a negative correlation with BTMs. The association with fragility fracture risk is less clear. Some studies found a positive association, some did not. A reason for this discrepancy may be the method (different assays) of evaluating serum sclerostin levels. According to Arasu et al. [26] and Ardawi et al. [16], fracture risk is amplified in subjects with high serum sclerostin levels and low BMD. According to a very recent study, the bone protein content of the Wnt antagonists sclerostin and Dkk1 was positively correlated with bone mass and bone strength in postmenopausal women with previous fragility fracture [30].

\section{Preclinical studies and animal models}

The knowledge that humans with genetic deficiencies of sclerostin have high bone mass induced in vitro and experimental investigations with the aim of developing anti-osteoporotic medication. Sclerostin knockout mice-imitating genetic deficiency of sclerostin-showed increases in bone formation, bone mass, and bone strength [31]. An overview of the effects of sclerostin deletion and overexpression on bone mass and bone strength in mice is given by $\mathrm{Ke}$ and coauthors [4]. Li et al. [32] mimicked postmenopausal osteoporosis and treated ovariectomized rats with a sclerostin-neutralizing antibody for 5 weeks. This procedure led to augmentation of trabecular, periosteal, endocortical, and intracortical bone formation. Treatment duration of 6 months corroborated the increases in bone mass and bone strength in ovariectomized rats, with more than $80 \%$ reductions in eroded surfaces $[33,34]$. In line with these investigations is a study which showed increases of BMD and improved bone architecture in aged male rats after 5 weeks of subcutaneous administration of the sclerostin antibody compared with placebo treatment [35]. Androgen-deficient rats that received a sclerostin antibody subcutaneously starting 3 months after orchiectomy experienced an increase in bone strength (gain in bone mineral content accompanied with maintenance of bone quality) after 6 weeks [36]. A different study group corroborated these results: In adult female rats, 4 weeks of subcutaneous injection of a monoclonal sclerostin antibody led to increased bone formation and decreased bone resorption in trabecular bone [37]. Previous antire- sorptive treatment with alendronate did not influence the anabolic effect of sclerostin antibody treatment in a negative way [38]. Transition from the sclerostin antibody application to vehicle application resulted in BMD loss; however, the transition to an antiresorptive agent after the cessation of sclerostin antibody treatment maintained the positive effect on BMD [39]. According to a colitis model, the treatment with a sclerostin antibody seems to counteract the accelerated bone loss associated with chronic inflammation [40].

The application of two monthly injections of a sclerostin neutralizing monoclonal antibody was evaluated in adolescent female cynomolgus monkeys. The effect of the antibody was dose dependent and BMD increases were up to $29 \%$ higher in treated ( 2 months) than untreated animals [41]. In ovariectomized cynomolgus monkeys, a one-year romosozumab treatment resulted in improvements in $\mathrm{BMD}$ as well as bone strength and maintained bone quality [42].

Fracture healing has been shown to be accelerated in SOST knockout mice as well as after sclerostin antibody treatment in wildtype rats $[43,44]$.

\section{Romosozumab}

\section{Clinical studies}

The first human study investigating romosozumaba humanized monoclonal antibody directed against the osteocyte-derived glycoprotein sclerostin-was a single-dose investigation of 72 healthy subjects. Men and postmenopausal women received different doses of AMG 785 (former name of romosozumab) subcutaneously or intravenously. The substance was well tolerated and bone formation increased, whereas bone resorption decreased in a dose-dependent manner, leading to increases in BMD (lumbar spine $+5.3 \%$, total hip $+2.8 \%$ ) by day 85 [45]. A 3-month multiple dose investigation evaluated the effect of subcutaneous injections ( 1 or $2 \mathrm{mg} / \mathrm{kg}$ every 2 weeks of 2 or $3 \mathrm{mg} / \mathrm{kg}$ every 4 weeks) of romosozumab in 32 osteopenic postmenopausal women and 16 osteopenic men [46]. Depending on the exposure of romosozumab, the bone formation marker procollagen type $1 \mathrm{~N}$-terminal propeptide (P1NP) transiently increased by $66-147 \%$ and the bone resorption marker C-terminal telopeptide of type 1 collagen (CTX) decreased by $15-50 \%$, leading to a BMD increase of the lumbar spine of $4-7 \%$. A high-resolution quantitative computed tomography (HRpQCT) analysis of $48 \mathrm{sub-}$ jects revealed a 9.5\% augmentation of trabecular BMD induced by 3 months of romosozumab therapy [47].

A phase 2 study including 419 postmenopausal women investigated five different dosing regimens of romosozumab $(70,140,210 \mathrm{mg}$ per month, 140 or $210 \mathrm{mg}$ every 3 months, or placebo injections). Additionally, patients of open-label study arms were 
Fig. 1 Schematic representation of bone turnover marker changes, the bone formation marker procollagen type $1 \mathrm{~N}$-terminal propeptide $(P 1 N P)$ and the bone resorption marker C-terminal telopeptide of type 1 collagen (CTX), during a one-year application of romosozumab; adapted from $[54,57,58]$

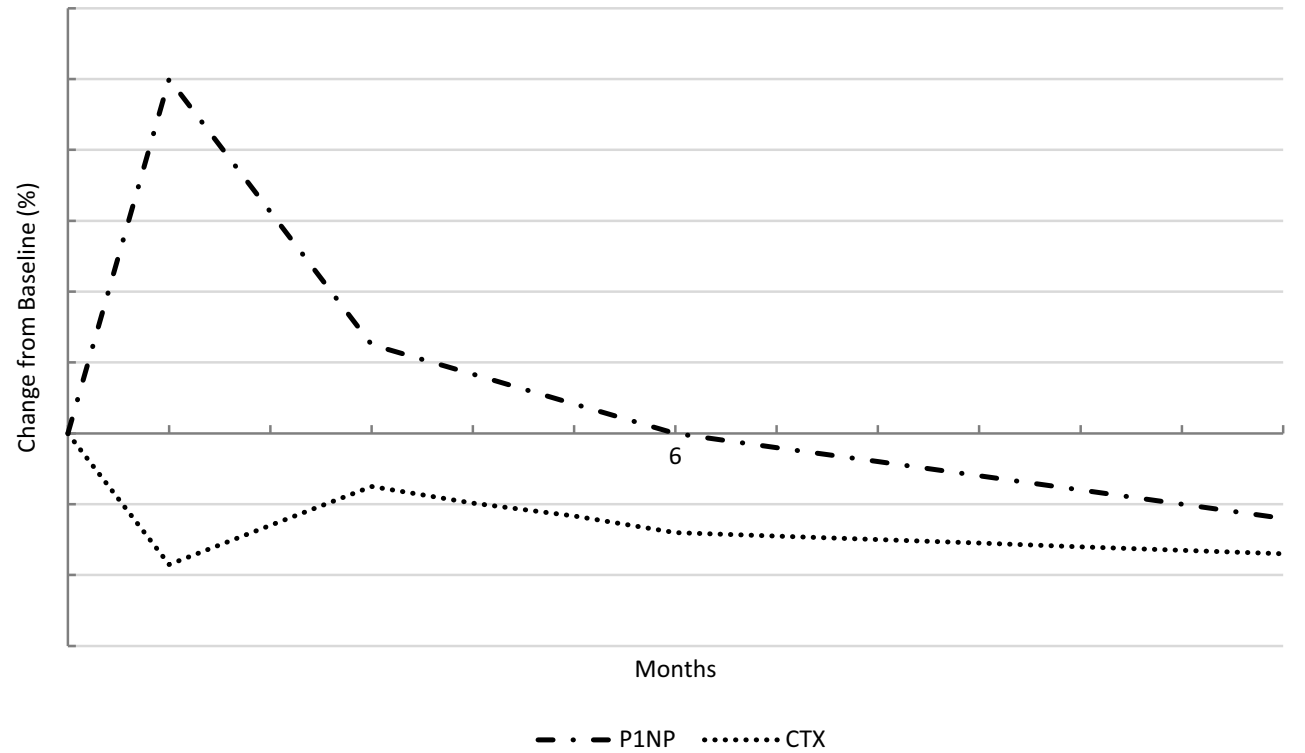

on alendronate or teriparatide treatment [48]. After 12 months, lumbar spine BMD, which was the primary endpoint, showed an increase at all dose levels $-11.3 \%$ with the $210 \mathrm{mg}$ per month dose. That was significantly greater than the $4.1 \%$ increase with alendronate and the $7.1 \%$ increase with teriparatide. P1NP values peaked after 4 weeks; thereafter, the bone formation marker decreased to or even below baseline levels. ß-CTX decreased within a week after the first romosozumab application and remained below baseline values during the whole study period. Analysis of a subset of the patients who had undergone QCT assessment revealed higher cortical vertebral volumetric BMD, higher trabecular hip volumetric BMD, and larger cortical bone mineral content gains with romosozumab compared with teriparatide at the spine and the hip [49]. Another substudy of this international phase II study evaluated bone strength gains using finite element analysis: Vertebral strength increased more for romosozumab compared with teriparatide $(27.3 \%$ versus $18.5 \%)$ and placebo $(27.3 \%$ versus $-3.9 \%$ ); femoral strength increased by $3.6 \%$ in the romosozumab group whereas it decreased by $0.7 \%$ in the teriparatide group and by $0.1 \%$ in the placebo group [50]. An extension of the international phase II study [48] was recently published [51]. Women in the romosozumab and placebo groups continued their treatment for an additional 12 months, the alendronate group transitioned to $140 \mathrm{mg}$ romosozumab each month, and the teriparatide group was no longer part of the study. After 24 months, women were rerandomized to $60 \mathrm{mg}$ denosumab or placebo every 6 months for another 12 months. Continuing romosozumab application for a second year led to further increases in BMD. However, these gains were a lot smaller than during the first year-at the lumbar spine $11.3 \%$ by month 12 and $15.1 \%$ by month 24 , at total hip $4.1 \%$ by month 12 and $5.4 \%$ by month 24 .
Further increases in BMD could be observed in participants who transitioned from romosozumab $210 \mathrm{mg}$ for 24 months to another 12 months of denosumab therapy. In subjects who received placebo after romosozumab treatment, BMD values decreased. Contrary to the lumbar spine and hip region, BMD at the $1 / 3$ radius deceased modestly from baseline till 24 months while receiving romosozumab. Subjects who had been treated with an oral bisphosphonate previously showed only slightly lower BMD increases than treatment-naïve subjects. Another phase II study lasting 12 months performed in Japan which included 252 postmenopausal osteoporotic women showed similar results concerning BMD gains and the course of bone turnover markers [52].

The treatment effects of romosozumab have also been compared with the treatment effects of teriparatide in a randomized open-label phase III study [53]. Four hundred thirty-six postmenopausal women who had been taking alendronate for at least 3 years were randomized to receive romosozumab $(210 \mathrm{mg} /$ month) or teriparatide $(20 \mu \mathrm{g} /$ day $)$. At the 12 -month appointment, the mean change in hip BMD was significantly higher in the former group $(+2.6 \%$ versus $-0.6 \%$ ). Integral volumetric bone mineral content was increased with romosozumab but unchanged with teriparatide, and finite element analysis also revealed greater gains in hip strength with romosozumab. The Fracture Study in Postmenopausal Women with Osteoporosis (FRAME) [54] is a double-blind study of 7180 postmenopausal osteoporotic women randomized to monthly subcutaneous injections of $210 \mathrm{mg}$ romosozumab or placebo. After 12 months, both treatment groups received subcutaneous injections of $60 \mathrm{mg}$ denosumab every 6 months for an additional 12 months. Within the first study year, the incidence of new vertebral fractures was reduced by $73 \%$ and the incidence of clinical fractures by $36 \%$ in the 
Table 2 Relevant side effects which occurred in phase III studies

\begin{tabular}{|c|c|c|c|}
\hline & FRAME [54] & ARCH [57] & BRIDGE [58] \\
\hline Duration & 12 months & 12 months & 12 months \\
\hline Patients & Women, $55-90$ years & Women, 55-90 years & Men, $55-90$ years \\
\hline Design & $\begin{array}{l}\text { Romosozumab }(n=3589) \text { vs. placebo } \\
(n=3591)\end{array}$ & $\begin{array}{l}\text { Romosozumab ( } n=2046) \text { vs. alendronate } \\
(n=2047)\end{array}$ & Romosozumab ( $n=163)$ vs. placebo $(n=82)$ \\
\hline $\begin{array}{l}\text { Geographic } \\
\text { region }\end{array}$ & $\begin{array}{l}\text { Central Europe, Eastern Europe, Latin } \\
\text { America, Western Europe, Australia. New } \\
\text { Zealand, Asia-Pacific, North America }\end{array}$ & $\begin{array}{l}\text { Central Europe, Eastern Europe, Middle East, } \\
\text { Latin America, Western Europe, Australia. } \\
\text { New Zealand, Asia-Pacific, South Africa, } \\
\text { North America }\end{array}$ & Europe, North America, Latin America, Japan \\
\hline $\begin{array}{l}\text { Injection site } \\
\text { reaction }\end{array}$ & 187 (5.2) vs. 104 (2.9) & $90(4.4)$ vs. $53(2.6)$ & 9 (5.5) vs. $3(3.7)$ \\
\hline Hypocalcemia & $1(<0.1)$ vs. 0 & $1(<0.1)$ vs. $1(<0.1)$ & 0 vs. 0 \\
\hline ONJ & $1(<0.1)$ vs. 0 & 0 vs. 0 & 0 vs. 0 \\
\hline $\begin{array}{l}\text { Atypical femoral } \\
\text { fracture }\end{array}$ & $1(<0.1)$ vs. 0 & 0 vs. 0 & 0 vs. 0 \\
\hline $\begin{array}{l}\text { Serious car- } \\
\text { diovascular } \\
\text { event }\end{array}$ & $44(1.2)$ vs. 41 (1.1) & 50 (2.5) vs. 38 (1.9) & $8(4.9)$ vs. $2(2.5)$ \\
\hline
\end{tabular}

romosozumab group. At 24 months, vertebral fracture risk was $75 \%$ lower in women who started with romosozumab and switched to denosumab. Nonvertebral fracture risk only showed a group-specific difference, favoring romosozumab treatment (hazard ratio 0.58 ) in a post hoc analysis after excluding Latin American study participants because in that region, the risk of non-vertebral fractures was much lower than at all other study sites [55]. Another endpoint of the FRAME study [54] was BMD gains, which were higher in FRAME participants who received romosozumab for 12 months and denosumab for another 12 months, and approximated after 2 years of therapy the BMD gains after 7 years of continuous denosumab application [56]. Another phase III study, the Active-Controlled Fracture Study in Postmenopausal Women with Osteoporosis at High Risk (ARCH) [57], which enrolled 4093 postmenopausal women with high fracture risk $(99 \%$ had a history of fragility fracture), compared 12 months of monthly subcutaneous romosozumab $(210 \mathrm{mg})$ with weekly oral alendronate $(70 \mathrm{mg})$. Afterwards, 12 months of alendronate therapy were added for all patients. After 12 months, vertebral fracture risk was $37 \%$, clinical fracture risk $28 \%$, and non-vertebral fracture risk $26 \%$ lower with romosozumab. After 24 months, vertebral fracture risk was $48 \%$ and clinical fracture risk $27 \%$ lower in the romosozumab-to-alendronate group than in the alendronate-to-alendronate group. Between-group differences of non-vertebral fracture risk (19\%) and hip fracture risk (38\%) did not reach statistical significance. The most recent phase III study, the BRIDGE study, included 245 men with a history of fragility fractures [58]. Concerning BMD as well as bone turnover markers, results of this placebocontrolled double-blind study were like those in postmenopausal women. BTM changes induced by ro- mosozumab therapy are schematically presented in Fig. 1.

\section{Safety}

During the development of a new medication, safety concerns are immanent. In a phase I study, one patient developed hepatitis, but increases in transaminase values have not been observed thereafter. In the phase II study published by McClung et al. [48], mild transient asymptomatic reductions in serum calcium were observed. Despite daily calcium and vitamin D supplementation, serum calcium levels decreased by $2 \%$ after 1 month of romosozumab therapy in the FRAME study [54]. One subject in the FRAME study and one subject in the ARCH study developed asymptomatic hypocalcemia. Injection site reactions varied between 4.4 and $5.5 \%$ for romosozumab application. Placebo-associated injection site reactions varied between 2.9 and $3.7 \%$. In the FRAME study, one subject of the romosozumab group developed osteonecrosis of the jaw and one subject suffered from an atypical femoral fracture. The number of serious cardiovascular adverse events was imbalanced in the ARCH and the BRIGE trials (Table 2). In 15 to $20 \%$ of the patients, anti-romosozumab antibodies were detected during the first year of therapy but this did not have any effect on safety or efficacy. Since the Wnt signaling pathway is essential for cellular proliferation in several tissues, concerns were raised that malignancy might be induced by antisclerostin therapy [59]. According to a rat lifetime pharmacology study, however, there are no indications that romosozumab administration poses a carcinogenic risk to humans [60].

To be on the safe side, McClung recommends refraining from romosozumab treatment in patients with hypocalcemia or vitamin D deficiency as well as in patients with the existence or the risk of skeletal 
metastases or other high bone remodeling conditions [61].

\section{Blosozumab \\ Clinical studies}

The safety and tolerability of blosozumab, another antibody against sclerostin, was studied in a randomized, placebo-controlled trial using single or multiple escalating doses for 8 weeks [62]. Blosozumab, which was given subcutaneously or intravenously to postmenopausal women, was well tolerated; bone formation markers increased and bone resorption decreased. An increase in BMD at the lumbar spine ( $+3.4 \%$ to $+7.7 \%$ ) could be observed after 85 days.

A phase II study included 120 postmenopausal women with low BMD [63]. The randomized, doubleblind, placebo-controlled trial investigated different doses of blosozumab given subcutaneously - up to $270 \mathrm{mg}$ every 2 weeks. The peak of the P1NP increase was reached 4 weeks after the first blosozumab application. CTX deceased and remained reduced through the whole study. According to follow-up after treatment cessation, BMD gradually decreases. However, lumbar spine and total hip BMD were still higher than initially placebo-treated women after 1 year [64].

\section{Safety}

In the phase II study [63], injection site reactions were more frequent in the blosozumab than in the placebo group (up to $40 \%$ vs. $10 \%$ ). Mild transient asymptomatic reductions in serum calcium were also observed in the blosozumab group. Serious adverse events were not related to the medication. Thirtyfive percent of the subjects developed anti-drug antibodies. Because of the injection site reactions in the study performed by Recker et al. [63], Eli Lilly developed alternate formulations. In the second phase I study, however, injection site reactions still occurred. According to a statement of the company, "Lilly was unable to identify a tolerable formulation of blosozumab to move into phase II studies."

\section{Further sclerostin antibodies}

Novartis also developed a sclerostin antibody, BPS804, also called setrusumab, which has been sold in the meantime to the Mereo Biopharma Group PLC. Searching in PubMed, no publications of BPS804 and postmenopausal osteoporosis are identified. Only patients suffering from hypophosphatasia and osteogenesis imperfecta have been treated with BPS804 so far $[65,66]$.

\section{Approval of Evenity (romosozumab)}

The registered trade name of romosozumab is Evenity. The first country to approve Evenity was Japan. There, in South Korea, and Australia Evenity is approved for the treatment of osteoporosis for women and men at a high risk of fracture. In Canada, osteoporotic postmenopausal women at high risk of fracture may be treated with Evenity. Since April 2019, this is also possible in the US, because at that timepoint, the Food and Drug Administration (FDA) gave the green light. However, according to the prescribing information [67] "Evenity may increase the risk of myocardial infarction, stroke and cardiovascular death. Evenity should not be initiated in patients who have had a myocardial infarction or stroke within the preceding year. Consider whether the benefits outweigh the risks in patients with other cardiovascular risk factors. If a patient experiences a myocardial infarction or stroke during therapy, Evenity should be discontinued." In Europe, approval of Evenity was granted by 2019-12-12. The indication is "Treatment of severe osteoporosis in postmenopausal women at high risk of fracture" [68].

\section{Conclusion}

Studies of patients with rare bone diseases and the understanding of the Wnt signaling pathway in bone metabolism identified the negative regulator of bone mass sclerostin as a potential target for the treatment of osteoporosis. Serum sclerostin levels are supposed to give a good impression of sclerostin levels in bone. However, circulating sclerostin is not currently evaluated in clinical routine, but rather only for scientific purposes. Two different antibodies against sclerostin have been investigated as potential treatment options for postmenopausal women. It has been proven that the sclerostin-binding monoclonal antibody romosozumab has advantageous effects on both aspects of bone volume regulation-it increases bone formation and reduces bone resorption. Within 1 year, BMD increases of more than $10 \%$ at the lumbar spine and as high as $7 \%$ in the hip region were observed. Vertebral as well as non-vertebral fractures were significantly reduced. Since the anabolic effect gradually gets lost after cessation of treatment, patients should go on with an antiresorptive treatment afterwards. At present, romosozumab is in clinical use in four countries. In Europe, we are still waiting for the final decision of the European Medicines Agency (EMA).

Funding Open access funding provided by Medical University of Vienna.

Conflict of interest K. Kerschan-Schindl declares that she has no competing interests.

Open Access This article is distributed under the terms of the Creative Commons Attribution 4.0 International License (http://creativecommons.org/licenses/by/4.0/), which per- 
mits unrestricted use, distribution, and reproduction in any medium, provided you give appropriate credit to the original author(s) and the source, provide a link to the Creative Commons license, and indicate if changes were made.

\section{References}

1. Parfitt AM, Villanueva AR, Foldes J, Rao DS. Relations between histologic indices of bone formation: implications for the pathogenesis of spinal osteoporosis. J Bone Miner Res. 1995;10:466-73.

2. Krishnan V, Bryant HU, MacDougald OA. Regulation of bone mass by Wnt signaling. JClin Invest. 2006;116:1202-9.

3. PinzoneJJ, HallBM, Thudi NK, Vonau M, QiangYW, RosolTJ, et al. The role of Dickkopf-1 in bone development, homeostasis, and disease. Blood. 2009;113:517-25.

4. Ke HZ, Richards WG, Li X, et al. Sclerostin and dickkopf 1 as therapeutic targets in bone diseases. Endocr Rev. 2012;33:747-83.

5. Van Buchem FS, Hadders HN, Ubbens R. An uncommon familial systemic disease of the skeleton: hyperostosis corticalis generalisata familiaris. Acta Radiol. 1955;44:109-20.

6. Truswell AS. Osteopetrosis with syndactyly, a morphologic variant of Albers-Schönberg disease. J Bone Joint Surg. 1958;40:208-18.

7. Balemans W, Ebeling M, Patel N, et al. Increased bone density in sclerosteosis is due to the deficiency of a novel secreted protein (SOST). Hum Mol Genet. 2001;10:537-43.

8. Van Lierop AH, Hamdy NAT, van Egmond ME, et al. Van Buchem Disease: clinical, biochemical, and densitometric features of patients and disease carriers. J Bone Miner Res. 2013;28:848-54.

9. Compton MS, Lee FY. A review of Osteocyte function and the emerging importance of Sclerostin. J Bone Joint Surg. 2014;96:1659-68.

10. Semenov M, Tamai K, HeX. SOST is a ligand for LRP5/6 and aWnt signaling inhibitor. J Biol Chem. 2005;260:770-5.

11. Drake MT, Srinivsan B, Mödder UI, et al. Effects of parathyroid hormone treatment on circulating sclerostin levels in postmenopausal women. J Clin Endocrinol Metab. 2010;95:5056-62.

12. Farr JN, Roforth MM, Fujita K, et al. Effects of age and estrogen on skeletal gene expression in humans as assessed by RNA sequencing. PLoSONE. 2015;10:e138347.

13. Rauner M, Sipos W, Pietschmann P. Age-dependent Wnt gene expression in bone and during the course of osteoblast differentiation. Age. 2008;30:273-82.

14. Modder UI, Clowed JA, Hoey K, et al. Regulation of circulating sclerostin levels by sex steroids in women and in men. JBone Miner Res. 2011;26:27-43.

15. Amrein K, Amrein S, Drexler C, et al. Sclerostin and its association with physical activity, age, gender, body composition, and bone mineral content in healthy adults. JClin Endocrinol Metab. 2012;97:48-54.

16. Ardawi MS, Rouzi AA, Al-Sibiani SA, et al. High sclerostin predicts the occurrence of osteoporotic fractures in postmenopausalwomen: the center of excellence for osteoporosisresearch study. JBone Miner Res. 2012;27:2592-602.

17. Moriwaki K, Matsumoto H, Tanishima S, et al. Association of serum bone- and muscle-derived factors with age, sex, body composition, and physical function in communitydwelling middle-aged and elderly adults: a cross-sectional study. BMC Musculoskelet Disord. 2019;20:276. https:// doi.org/10.1186/s12891-019-2650-9.

18. Kalem MN, Kalem Z, Akgum N, et al. The relationship between postmenopausal women's sclerostin levels andtheir bone density, age, body mass index, hormonal status, and smoking and consumption of coffee and dairy products. Arch Gynecol Obstet. 2017;295:785-93.

19. Dawson-Hughes B, Harris SS, Ceglia L, et al. Serum sclerostin levels vary with season. J Clin Endocrinol Metab. 2014;99:E149-E52.

20. Robling AG, Niziolek PJ, Baldidge LA, et al. Mechanical stimulation of bone in vivo reduces osteocyte expression of Sost/sclerostin. JBiolChem. 2008;283:5866-75.

21. Lin C, Jiang X, Dai Z, et al. Sclerostin mediated bone response to mechanical unloading through antagonizing Wnt/ß-catenin signaling. J Bone Miner Res. 2009;24:1651-61.

22. Hinton PS, Nigh P, Thyfault J. Serum sclerostin deceases following 12 months of resistance or jump-training in men with lowbone mass. Bone. 2017;96:85-90.

23. Kerschan-Schindl K, Thalmann M, Weiss E, et al. Changes in serum levels of myokines and Wnt-antagonists after an ultramarathon race. PLoS ONE. 2015;10:e132478.

24. Kouvelioti R, Kurgan N, Falk B, et al. Cytokine and sclerostin response to high-intensity interval running versus cycling. Med Sci Sports. 2019; https://doi.org/10.1249/ MSS.0000000000002076.

25. GaudioA, PennisiP, Bratengeier C, etal. Increased sclerostin serumlevels associated with boneformation and resorption markers in patients with immobilization-induced bone loss. JClin Endocrinol Metab. 2010;95:2248-53.

26. Arasu A, Cawthon PM, LuiLY, etal. Serum sclerostin and risk of hip fracture in older Causasian women. JClin Endocrinol Metab. 2012;97:2027-32.

27. Garnero P, Sornay-Rendu E, Munoz F, et al. Association of serum sclerostin with bone mineral density, bone turnover, steroid and parathyroid hormones, and fracture risk in postmenopausal women: the OFELY study. Osteoporos Int. 2013;24:489-94.

28. Szulc P, Bertholon C, Borel O, et al. Lower fracture risk in older men with higher sclerostin concentration: a prospective analysis from the MINOS study. J Bone Miner Res. 2013;28:855-64.

29. Amrein K, Dobnig H, Wagner D, et al. Sclerostin in institutionalized elderly women: associations with quantitative bone ultrasound, bone turnover, fractures, and mortality. JAm Geriatr Soc. 2014;62:1023-9.

30. Ueland T, Stilgren L, Bollerslev J. Bone matrix levels of dickkopf and sclerostin are positively correlated with bone mass and strength in postmenopausal osteoporosis. Int J Mol Sci. 2019;20:2896. https://doi.org/10.3390/ijms20122896.

31. Li X, Ominsky MS, Niu QT, et al. Targeted deletion of the sclerostin gene in mice results in increased bone formation and bone strength. J Bone Miner Res. 2008;23:860-9.

32. LiX, OminskyMS, Warmington KS, etal. Sclerostin antibody treatment increases bone formation, bone mass and bone strength in a rat model of postmenopausal osteoporosis. J Bone Miner Res. 2009;24:578-88.

33. Li X, Warmington KS, Asuncion FJ, et al. Progressive increasesinbonemassandbonestrengthin an ovarectomized rat model of osteoporosis after 26 weeks of treatment with a sclerostin antibody. Endocrinology. 2014;155:4785-97.

34. Stoliuna M, Dwyer D, Niu QT, et al. Temporal changes in systemic and local expression of bone turnover markers during six months of sclerostin antibody administration to ovariectomized rats. Bone. 2014;67:305-13.

35. Li X, Warmington KS, Niu QT, et al. Inhibition of sclerostin by monoclonal antibody increases bone formation, bone mass, and bone strength in aged male rats. JBone Miner Res. 2010;25:2647-56.

36. Li X, Ominsky MS, Villsenor KS, et al. Sclerostin antibody reverses bone loss by increasing bone formation and de- 
creasing bone resorption in rat model of male osteoporosis. Endocrinology. 2018;59:260-71.

37. TianXY, SetterbergRB, LiX, etal. Treatment with a sclerostin antibody increases cancellous bone formation and bone mass regardless of marrow composition in adult female rats. Bone. 2010;47:529-33.

38. Li X, Ominsky MS, Warmington KS. Increased bone formation and bone mass induced by of sclerostin antibody is not affected by retreatment or cotreatment with alendronatein osteopenic, ovariectomized rats. Endocrinology. 2011;152:3312-22.

39. Ominsky MS, Boyce RW, Li X, et al. Effects of sclerostin antibodies in animal models of osteoporosis. Bone. 2017;96:63-75.

40. Eddleston A, Marenzana M, Moore AR, et al. A short treatment with an antibody to sclerostin can inhibit bone loss in an ongoing model of colitis. J Bone Miner Res. 2009;24:1662-71.

41. Ominsky MS, Vlasserros F, Jolette J, et al. Two doses of sclerostin antibody in cynomolgus monkeys increases bone formation, bone mineral density, and bone strength. J Bone Miner Res. 2010;25:948-59.

42. Ominsky MS, Boyd SK, Varela A, et al. Romosozumab improves bone mass and strength while maintaining bone quality in ovariectomized cynomolgus monkeys. J Bone Miner Res. 2016;32:788-801.

43. Li C, Ominsky MS, Tan HL, et al. Increased callus mass and enhanced strength during fracture healing in mice lacking the sclerostingene. Bone. 2011;49:1178-85.

44. Ominsky MS, Li C, Li X, et al. Inhibition of sclerostin by monoclonal antibody enhances bone heling and improves bone density and strength of nonfractured bones. J Bone Miner Res. 2011;26:1012-21.

45. Padhi D, Jang G, Stouch B, et al. Single-dose, placebocontrolled, randomized study of AMG 785, a sclerostin monoclonal antibody. J Bone Miner Res. 2011;26:19-26.

46. Padhi D, Allison M, Kivitz AJ, et al. Multiple doses of sclerostin antibody romosozumab in healthy men and postmenopausal women with low bone mass: a randomized, double-blind, placebo-controlled study. J Clin Pharmacol. 2014;54:168-78.

47. Graeff C, Campbell GM, Pena J, et al. Administration of romosozumab improves vertebral trabecular and cortical bone as assessed with quantitative computed tomography and finite element analysis. Bone. 2015;81:364-9.

48. McClung MR, Grauer A, Boonen S, et al. Romosozumab in postmenopausal women with low bone mineral density. NEng J Med. 2014;370:412-20.

49. Genant HK, Engelke K, Bolognese MA, et al. Effects of romosozumab compared with teriparatide on bone density and mass at the spine and hip in postmenopausal women with low bone mass. J Bone Miner Res. 2017;32:181-7.

50. Keaveny TM, Crittenden DB, Bolognese MA, et al. Greater gains in spine and hip strength for romosozumab compared with teriparatide in postmenopausal women with low bone mass. J Bone Miner Res. 2017;32:1956-62.

51. McClung MR, Brown JP, Diez-Perez A, et al. Effects of 24 months of treatment with romosozumab followed by 12 months of denosumab of placebo in postmenopausal women with low bone mineral density: a randomized, double-blind, phase 2, parallel group study. J Bone Miner Res. 2018;33:1397-406.

52. Ishibashi H, Crittenden DB, Miyauchi A, et al. Romosozumab increases bone mineral density in postmenopausal Japanese women with osteoporosis. Bone. 2017;103:209-15.
53. Langdahl B, LibanatiC, Crittenden DB, et al. Romosozumab (sclerostin monoclonal antibody) versus teriparatide in postmenopausal women with osteoporosis transitioning from bisphosphonate therapy: a randomised, open-label, phase 3 trial. Lancet. 2017;390:1585-93.

54. Cosman F, Crittenden DB, Adachi JD, et al. Romosozumab treatment in postmenopausal women with osteoporosis. NEng J Med. 2016;375:1532-43.

55. Cosman F, Crittenden DB, Ferrari S, et al. Romosozumb FRAME Study: a post hoc analysis of the role of regional backgroundfracture riskonnonvertebral fracture outcome. JBone Miner Res. 2018;33:1407-16.

56. Cosman F, Crittenden DB, Ferrari S, et al. FRAME Study: The foundation effect of building bone with 1 year of romosozumab leads to continued lower fracture risk after transition to denosumab. J Bone Miner Res. 2018;33:1219-26.

57. Saag KG, Petersen J, Brandi MI, et al. Romosozumab or alendronate for fracture prevention in women with osteoporosis. NEng J Med. 2017;377:1417-27.

58. Lewiecki EM, Blicharski T, Goemaere S, et al. A phase III randomized placebo-controlled trial to evaluate efficacy and safety of romosozumab in men with oteoporosis. J Clin Endocrinol Metab. 2018;103:3183-93.

59. Krishnamarthy N, Kurzrock R. Targeting the Wnt/betacatenin pathwayin cancer: update on effects and inhibitors. Cancer Treat Rev. 2018;62:50-60.

60. Chouinard L, Felx M, Mellal N, et al. Carcinogenicity risk assessment of romosozumab: a review of scientific weightof evidence and findings in a rat lifetime pharmacology study. Reg Toxicol Pharmakol. 2016;81:212-22.

61. McClung MR. Romosozumab for the treatment of osteoporosis. Review article. Osteoporos Sarcopenia. 2018;4:11-5.

62. McColm J, Hu L, Womack T, et al. Single- and multiple-dose randomized studies ofblosozumab, a monoclonal antibody against sclerostin, in healthy postmenopausal women. J Bone Miner Res. 2014;29:935-43.

63. Recker RR, Benson CT, Matsumoto T, et al. A randomized, double blind phase 2 clinical trial of blosozumab, a sclerostin antibody, in postmenopausal women with low bone mineral density. J Bone Miner Res. 2015;30:216-24.

64. Recknor CP, Recker R, Benson CT, et al. The effect of discontinuing treatment with blosozumab: follow-up results of a phase 2 randomized clinical trial in postmenopausal women with low bone mineral density. J Bone Miner Res. 2015;30:1717-25.

65. Seefried L, Baumann J, Hemsley S, Hofmann C, KunstmannE, KieseB, etal. Efficacy of anti-sclerostinmonoclonal antibody BPS804 in adult patients with hypophosphatasia. JClin Invest. 2017;127:2148-58.

66. Glorieux FH, Devogelaer JP, Durigova M, Goemaere S, Hemsley S, Jakob F, et al. BPS804 anti-sclerostin antibody in adults with moderate osteogenesis imperfecta: results of a randomized phase 2a trial. J Bone Miner Res. 2017;32:1496-504.

67. EVENITYTM (romosozumab-aqqg) U.S. Prescribing Information https://www.pi.amgen.com/ /media/amgen/ repositorysites/pi-amgen-com/evenity/evenity_pi_hcp_ english.ashx. Accessed 28.11.2019

68. https://www.ema.europa.eu/en/medicines/human/ summaries-opinion/evenity. Accessed 28.11.2019

Publisher's Note Springer Nature remains neutral with regard to jurisdictional claims in published maps and institutional affiliations. 